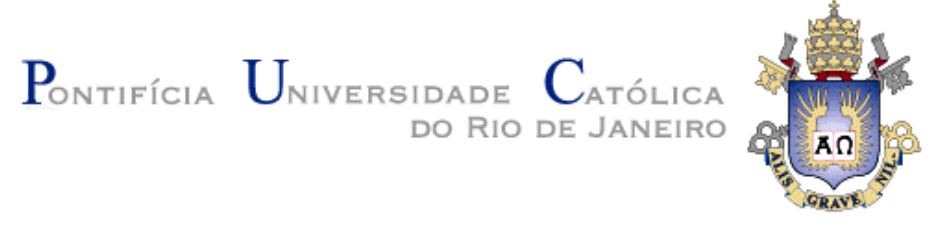

Leandro dos Santos Nazareth

\title{
Sistema para Consultas sobre Banco de Dados Relacional Baseado em Palavras-Chave
}

\author{
Dissertação de Mestrado
}

Dissertação apresentada ao Programa de Pós-Graduação em Informática do Departamento de Informática da PUCRio como parte dos requisitos parciais para obtenção do título de Mestre em Informática.

Orientador: Prof. Marco Antonio Casanova 


\title{
Pontifícia U Uiversidade $\mathrm{C}_{\text {atólica }}$
}

\section{Leandro dos Santos Nazareth}

\section{Sistema para Consultas sobre Banco de Dados Relacional Baseado em Palavras-Chave}

\begin{abstract}
Dissertação apresentada como requisito parcial para a obtenção do grau de Mestre pelo Programa de Pós-graduação em Informática do Departamento de Informática do Centro Técnico e Científico da PUC-Rio. Aprovada pela Comissão Examinadora abaixo assinada.
\end{abstract}

Prof. Marco Antonio Casanova

Orientador

Departamento de Informática - PUC-Rio

Prof. Antonio Luz Furtado Departamento de Informática - PUC-Rio

Prof. Melissa Lemos Departamento de Informática - PUC-Rio

Prof. José Eugenio Leal Coordenador Setorial do Centro Técnico Científico - PUC-Rio 
Todos os direitos reservados. É proibida a reprodução total ou parcial do trabalho sem autorização da universidade, do autor e do orientador.

\section{Leandro dos Santos Nazareth}

Nasceu em 1982, Iniciou o curso de Bacharelado em Informática da PUC-Rio (Pontifícia Universidade Católica do Rio de Janeiro) em 2000, graduou-se em 2003. Atua como Analista de Sistemas no laboratório Tecgraf (Tecnologia em Computação Gráfica) desde 2000.

Ficha Catalográfica

Nazareth, Leandro dos Santos

Sistema para consultas sobre banco de dados relacional baseado em palavras-chave / Leandro dos Santos Nazareth ; orientador: Marcos Antonio Casanova. - 2008. 110 f. : il. (col.) ; $30 \mathrm{~cm}$

Dissertação (Mestrado em Informática)-Pontifícia Universidade Católica do Rio de Janeiro, Rio de Janeiro, 2008.

Inclui bibliografia

1. Informática - Teses. 2. Sistema de gerenciamento de banco de dados. 3. SGBD. 4. Relacional. 5. Busca. 6. Palavras-chave. 7. Geração automática de consulta. I. Casanova, Marco Antonio. II. Pontifícia Universidade Católica do Rio de Janeiro. Departamento de Informática. III. Título. 
Este trabalho é dedicado aos meus pais e a minha esposa, Mariana, que estiveram sempre ao meu lado nos momentos mais difíceis dando força e souberam compreender minha ausência. 


\section{Agradecimentos}

Aos meus pais que sempre me mostraram a importância dos meus estudos e que muitas vezes fizeram o impossível para que eu chegasse até aqui.

Aos meus amigos que sempre estão ao meu lado quando preciso.

Aos meus colegas de trabalho que entenderam muitas vezes a minha ausência.

Ao Tecgraf, empresa onde trabalho, que sempre me estimulou e motivou durante o mestrado.

A Anelise Lara que sempre confiou em meu trabalho e possibilitou os meus estudos.

Principalmente a minha esposa, Mariana por sempre me ajudar nas horas mais difíceis sempre me motivando e me dando muita alegria. 


\section{Resumo}

Nazareth, Leandro dos Santos; Casanova, Marco Antonio; Sistema para Consultas sobre Banco de Dados Relacional Baseado em PalavrasChave. Rio de Janeiro, 2008. 110p. Dissertação de Mestrado Departamento de Informática, Pontifícia Universidade Católica do Rio de Janeiro.

Esta dissertação descreve um sistema desenvolvido que permite a criação e execução de consultas a partir de palavras-chave sobre um banco de dados relacional. O sistema recebe palavras-chave quaisquer e tenta criar consultas que podem ser executadas em um Sistema de Gerenciamento de Banco de dados (SGBD). Para realizar esta geração automática de consultas o sistema utiliza os dados do catálogo da base de origem. O sistema permite assim efetuar consultas em um SGBD sem o conhecimento de uma linguagem de consultas, como SQL, e sem conhecimento do modelo do banco de dados.

\section{Palavras-chave}

Sistema de Gerenciamento de Banco de Dados, SGBD, Relacional, Busca, Palavras-chave, Geração Automática de Consulta. 


\section{Abstract}

Nazareth, Leandro dos Santos; Casanova, Marco Antonio; System for Keyword Search in Relational Database. Rio de Janeiro, 2008. 110p. Msc. Dissertation - Departamento de Informática, Pontifícia Universidade Católica do Rio de Janeiro.

This dissertation describes a developed system that allows the creation and execution of searches from keywords in a relational database. The system receives any keywords and tries to create queries that can be executed in database. To perform this automatic generation of queries the system uses the information of the catalogue of the source database. The system allows to make queries in a database without the knowledge of a language queries, like SQL, and the model from the database.

\section{Keywords}

Relational database, search, keyword, database, relational. 


\section{Sumário}

1 Introdução 15

1.1. Motivação 15

1.2. Abordagem proposta 17

1.3. Organização da dissertação 18

2 Trabalhos Relacionados 19

2.1. Introdução 19

$\begin{array}{ll}\text { 2.2. BANKS } & 19\end{array}$

2.3. DBXplorer 20

2.4. DESANA 21

2.5. $L A B R A D O R \quad 21$

2.6. Comparativo 22

3 Arquitetura do Sistema 23

3.1. Visão geral 23

3.2. Estrutura das tabelas do sistema 24

3.3. Tipos de usuários 25

3.4. Tecnologia utilizada 27

3.5. Etapas 28

3.5.1. Etapa de Publicação 29

3.5.2. Etapa de Busca 31

4 Administração $\quad 35$

4.1. Interface 35

4.2. Criação e Edição de Aplicações (Publicação) 36

5 Busca 42

5.1. Tratamento das Palavras-Chave de Entrada 42

5.2. Agrupamento de Palavras-Chave 43 
5.3. Localização e Mapeamento das Referências 44

5.4. Criação das Consultas 48

5.5. Execução das Consultas 56

6 Exemplos $\quad 58$

6.1. Exemplo de um Banco de Dados de Publicações 58

6.1.1. Estrutura Banco de Dados de Publicações 58

6.1.2. Conteúdo Banco de Dados de Publicações 59

6.1.2.1. Conteúdo Tabela Cidade do Banco de Dados de Publicações 59

6.1.2.2. Conteúdo Tabela Categoria do Banco de Dados de Publicações59

6.1.2.3. Conteúdo Tabela Autor do Banco de Dados de Publicações 60

6.1.2.4. Conteúdo Tabela Livro do Banco de Dados de Publicações 61

6.1.3. Execução do Sistema Banco de Dados de Publicações 62

6.1.3.1. Busca 1

6.1.3.2. Busca $2 \quad 65$

$\begin{array}{ll}\text { 6.1.3.3. Busca } 3 & 74\end{array}$

6.1.3.4. Busca $4 \quad 76$

6.2. Exemplo de um Banco de Dados de Venda 78

6.2.1. Estrutura Banco de Dados de Venda 78

6.2.2. Conteúdo Banco de Dados de Venda 79

6.2.2.1. Conteúdo Tabela Produto do Banco de Dados de Venda 80

6.2.2.2. Conteúdo Tabela Loja do Banco de Dados de Venda 81

6.2.2.3. Conteúdo Tabela Produto_Loja do Banco de Dados de Venda 82

6.2.2.4. Conteúdo Tabela Vendedor do Banco de Dados de Venda 83

6.2.2.5. Conteúdo Tabela Venda do Banco de Dados de Venda 84

6.2.3. Execução do Sistema Banco de Dados de Venda 85

6.2.3.1. Busca 1

$\begin{array}{ll}\text { 6.2.3.2. Busca } 2 & 87\end{array}$

$\begin{array}{ll}\text { 6.2.3.3. Busca } 3 & 90\end{array}$

7 Conclusões 93

7.1. Contribuições 93

$\begin{array}{ll}\text { 7.2. Trabalhos futuros } & 94\end{array}$ 
8 Referências Bibliográficas

9 Anexo 98

9.1. Scripts de Criação do Banco de Dados do Sistema 98

9.2. Scripts Exemplo de Publicações 102

9.2.1. Scripts de Criação das Tabelas do Exemplo de Publicações 102

9.2.2. Scripts de Inserção das Tabelas do Exemplo de Publicações 104

9.3. Scripts Exemplo de Venda de Produtos 107

9.3.1. Scripts de Criação das Tabelas do Exemplo de Publicações 107

9.3.2. Scripts de Inserção do Exemplo de Venda de Produtos 109 


\section{Lista de figuras}

Figura 1: Estrutura do banco de dados do sistema $\quad 24$

Figura 2: Funcionamento do sistema $\quad 27$

Figura 3: Etapa de publicação 30

Figura 4: Etapa de busca 34

Figura 5: Interface do Sistema 35

Figura 6: Montagem da Interface Principal 36

Figura 7: Página Principal Administrativa 37

Figura 8: Página de Edição de Aplicação 38

Figura 9: Pseudo-código da Página de Edição de Aplicação 39

Figura 10: Página de Edição da Aplicação Publicações 40

Figura 11: Pseudo-código do Tratamento de Entrada 43

Figura 12: Pseudo-código do Agrupamento de Palavras entre Aspas 44

Figura 13: Tela de associação das palavras $\quad 46$

Figura 14: Pseudo-código da Busca de Referências para as Palavras 48

Figura 15: Pseudo-código Cria Relação Palavras e Banco de Dados 49

Figura 16: Pseudo-código Cria Quantidade de Possíveis Consultas 50

Figura 17: Associação entre palavras e referências 50

Figura 18: Matriz de associação

Figura 19: Montagem da Matriz de Associação 52

Figura 20: Verifica se Existe Caminho Entre Tabelas 53

Figura 21: Geração das Consultas Válidas

Figura 22: Interface de consultas geradas 56

Figura 23: Estrutura Exemplo Publicações 58

Figura 24: Conteúdo Tabela Cidade 59

Figura 25: Conteúdo Tabela Categoria $\quad 59$

Figura 26: Conteúdo Tabela Autor 60

Figura 27: Conteúdo Tabela Livro $\quad 61$

Figura 28: Associações Sugeridas para Busca 1 de Publicações 62

Figura 29: Associações Realizadas para Busca 1 de Publicações 62 
Figura 30: SQL Gerado para Consulta 1 da Busca 1 de Publicações

Figura 31: Resultado Gerado para Consulta 1 da Busca 1 de Publicações 63

Figura 32: SQL Gerado para Consulta 2 da Busca 1 de Publicações 64

Figura 33: Resultado Gerado para Consulta 2 da Busca 1 de Publicações 64

Figura 34: Associações Sugeridas para Busca 2 de Publicações 65

Figura 35: Associações Realizadas para Busca 2 de Publicações 65

Figura 36: SQL Gerado para Consulta 1 da Busca 2 de Publicações 66

Figura 37: Resultado Gerado para Consulta 1 da Busca 2 de Publicações 67

Figura 38: SQL Gerado para Consulta 2 da Busca 2 de Publicações 67

Figura 39: Resultado Gerado para Consulta 2 da Busca 2 de Publicações 68

Figura 40: SQL Gerado para Consulta 3 da Busca 2 de Publicações 68

Figura 41: Resultado Gerado para Consulta 3 da Busca 2 de Publicações 69

Figura 42: SQL Gerado para Consulta 4 da Busca 2 de Publicações 69

Figura 43: Resultado Gerado para Consulta 4 da Busca 2 de Publicações $\quad 70$

Figura 44: SQL Gerado para Consulta 5 da Busca 2 de Publicações 70

Figura 45: Resultado Gerado para Consulta 5 da Busca 2 de Publicações 71

Figura 46: SQL Gerado para Consulta 6 da Busca 2 de Publicações 71

Figura 47: Resultado Gerado para Consulta 6 da Busca 2 de Publicações 72

Figura 48: Alternativa de Associações Realizadas da Busca 2 de Publicações 72

Figura 49: SQL Gerado para Consulta Alternativa da Busca 2 de Publicações 73

Figura 50: Resultado para Consulta Alternativa da Busca 2 de Publicações 73

Figura 51: Associações Sugeridas para Busca 3 de Publicações 74

Figura 52: Associações Realizadas para Busca 3 de Publicações 75

Figura 53: SQL Gerado para Consulta 1 para Busca 3 de Publicações 76

Figura 54: Associações Sugeridas para Busca 4 de Publicações 77

Figura 55: Estrutura Exemplo Venda de Produtos 78

Figura 56: Conteúdo Tabela Produto 80

Figura 57: Conteúdo Tabela Loja $\quad 81$

Figura 58: Conteúdo Tabela Produto_Loja 82

Figura 59: Conteúdo Tabela Vendedor 83

Figura 60: Conteúdo Tabela Venda $\quad 84$

Figura 61: Associações Sugeridas para Busca 1 de Venda 85

Figura 62: Associações Realizadas para Busca 1 de Venda 86 
Figura 63: SQL Gerado para Consulta 1 para Busca 1 de Venda 86

Figura 64: Resultado para Consulta 1 da Busca 1 de Venda 87

Figura 65: Associações Sugeridas para Busca 2 de Venda 87

Figura 66: Associações Realizadas para Busca 2 de Venda 88

Figura 67: SQL Gerado para Consulta 1 para Busca 2 de Venda 89

Figura 68: Resultado para Consulta 1 da Busca 2 de Venda 89

Figura 69: Associações Sugeridas para Busca 3 de Venda 90

Figura 70: Associações Realizadas para Busca 3 de Venda 90

Figura 71: SQL Gerado para Consulta 1 para Busca 3 de Venda 91

Figura 72: Resultado para Consulta 1 da Busca 3 de Venda 92

Figura 73: Script de Criação da Tabela Aplicacao 99

Figura 74: Script de Criação da Tabela Objeto 100

Figura 75: Script de Criação da Tabela Objeto_Coluna 101

Figura 76: Script de Criação da Tabela Objeto_Relacao 102

Figura 77: Script de Criação da Tabela Cidade 102

Figura 78: Script de Criação da Tabela Categoria 103

Figura 79: Script de Criação da Tabela Autor 103

Figura 80: Script de Criação da Tabela Livro 104

Figura 81: Script de Inserção na Tabela Cidade 104

Figura 82: Script de Inserção na Tabela Categoria 105

Figura 83: Script de Inserção na Tabela Autor 105

Figura 84: Script de Inserção na Tabela Livro 106

Figura 85: Script de Criação da Tabela Produto 107

Figura 86: Script de Criação da Tabela Loja 107

Figura 87: Script de Criação da Tabela Produto_Loja 108

Figura 88: Script de Criação da Tabela Vendedor 108

Figura 89: Script de Criação da Tabela Venda 109

Figura 90: Script de Inserção na Tabela Produto 109

Figura 91: Script de Inserção na Tabela Loja 110

Figura 92: Script de Inserção na Tabela Produto_Loja 110

Figura 93: Script de Inserção na Tabela Vendedor 111

Figura 94: Script de Inserção na Tabela Venda 111 